\title{
Sibirya'da iç ve dış mekânlarda kullanılan Sibirya çamı odununun yüzey pürüzlülüğü parametreleri ve shore $D$ sertlik değeri üzerine ısıl işlemin etkisi
}

Ümit Ayata@

\section{$\ddot{O} z$}

Sibirya çamının Sibirya'da yetiştiği ve odununun hafif, yumuşak, iyi işlenebilen özelliği, düzgünlüğü ve güzel doku yapısı ile kalem yapımında, inşaat alanlarında, ev yapımında, müzik aletleri yapımında, mobilya alanında ve çeşitli el sanatlarının yapımında kullanıldığı bilinmektedir. $\mathrm{Bu}$ araştırmada, $212^{\circ} \mathrm{C}$ 'de 2 saat sürede 1 sıl işlem (ThermoWood) uygulanmış ve uygulanmamış Sibirya çamı (Pinus sibirica) odununda hazırlanmış olan örnekler üzerinde farkl1 zimparalar $(80,100,120,150,180$ ve 220 numaralı) uygulandıktan sonra yüzey pürüzlülügüne ait parametreleri $\left(R_{\mathrm{a}}, R_{\mathrm{z}}\right.$ ve $\left.R_{\mathrm{q}}\right)$ ve shore $\mathrm{D}$ sertlik değerleri araştırılmıştır. Araştırma sonuçlarına göre, pürüzlülük parametreleri ve shore D sertlik değerleri isıl işlem ile azalmıştır. Isıl işlem sonrası shore D sertlik değerinde $\% 20.43$ 'lük, $R_{\text {a }}$ parametrelerinde 80 numarada \%22.16'lik, 100 numarada \%26.25'lik, 120 numarada \%36.42'lik, 150 numarada \%35.71'lik, 180 numarada \%36.38'lik ve 220 numarada \%50.88'lik oranlarda azalmalar meydana gelmiştir. Buna ek olarak, zımpara numarasının artması ile pürüzlülük değerlerinin de azaldığı, yüzey kalitesinde artış olduğu ve iyi sonuçlara ulaşıldığ belirlenmiştir.

Anahtar kelimeler: Sibirya çamı, Pinus sibirica, shore D sertlik, yüzey pürüzlülügü,, 1sıl işlem

\section{The effect of heat treatment on the surface roughness parameters and shore D hardness of Siberian pine wood used indoors and outdoors in Siberia}

\begin{abstract}
It is known that Siberian pine grows in Siberia and its wood is used in pencil making, construction sites, house construction, musical instruments, furniture and various handicrafts with its light, soft, well-workable feature, smoothness and beautiful texture. In this study, the parameters $\left(R_{\mathrm{a}}, R_{\mathrm{z}}\right.$ and $\left.R_{\mathrm{q}}\right)$ of surface roughness and shore $\mathrm{D}$ hardness values were investigated after applying different abrasives (80, 100, 120, 150, 180 and 220 of number of sand) were applied on samples prepared from Siberian pine (Pinus sibirica) wood that was heat-treated (ThermoWood) at $212^{\circ} \mathrm{C}$ for 2 hours and untreated. According to the results of the research, the roughness parameters and shore $\mathrm{D}$ hardness values decreased by heat treatment. After heat treatment, there was a decrease of $20.43 \%$ in shore D hardness value, $22.16 \%$ in $R_{\text {a }}$ parameters in 80 number, $26.25 \%$ in 100 number, $36.42 \%$ in 120 number, $35.71 \%$ in 150 number, $36.38 \%$ in 180 number and $50.88 \%$ in 220 number. In addition, it had been observed that with the increase of the sanding number, the roughness values decreased, there was a change in the surface quality and good results were determined.
\end{abstract}

Keywords: Siberian pine, Pinus sibirica, shore D hardness, surface roughness, heat treatment 


\section{Giriş}

Batı ve Doğu Sibirya'da yetişen Sibirya çamı (Pinus sibirica) (Rogachev ve Salakhutdinov, 2015), Pinaceae familyası ve Strobus alt cinsine ait (Shikov ve ark., 2004) tek evcikli olup, rüzgarla tozlanan (Kuznetsova, 2007, Zhuk ve Goroshkevich, 2012) bir türdür. 35 - 40 m boya ulaşabilen ve tam olgunlaştığında 1.8 m'ye kadar gövde çapına sahip, yaprak dökmeyen bir ağaç türüdür. Ağırlıklı olarak Sibirya, Urallar ve Avrupa'nın kuzey bölgelerinde yetişmektedir. Sibirya çam kozalakları yaklaşık $5-9 \mathrm{~cm}$ uzunluğunda iken, tohumlar 9 - $12 \mathrm{~cm}$ uzunluğa kadar büyüyebilir (Shikov ve ark., 2004). İlk çağlardan beri, yumuşak odun yapısı ve yemişlerinin faydalı besleyici özellikleri sebebiyle çok değerli olmuştur. Sibirya çamının değeri, endüstriyel teknolojiler geliştirildikçe daha da artmıştır. Çünkü bu ağaç, terebentin ve kolofoniye yol açmak için işlenen mükemmel bir oleoresin kaynağı olmaktadır (Rogachev ve Salakhutdinov, 2015).

Odunu hafif, yumuşak, iyi işlenebilen özelliği, düzgünlüğü ve güzel dokusu ile değerlidir. Ahşabı kalem yapımında ev yapımında, mobilya alanında, müzik aletleri ve çeşitli el sanatlarının yapımında (Matveeva ve ark., 2003), inşaat alanlarında (Wang, 2011) kullanılmaktadır. Bu ağacın tüm ağaç kısımları (ağaç kabuğu, iğneler, odunu ve findık) halk hekimliğinde kullanılmaktadır. Fındığı yağı bakteriostatik ve yara iyileştirici etkilere sahiptir. Ezilmiş findığından yapılan alkollü tentür, tıpta eklem romatizmasının tedavisinde kullanılmıştır. Günümüzde bazı ilaçların hazırlanmasında findığı hammadde olarak kullanılmaktadır (Shikov ve ark., 2004). Ağacın besleyici tohumları ise kuru meyve ve yağda yaygın olarak kullanılmaktadır (Wang, 2011).

Bu ağaç türünde, yıllık halka genişliği $2.20 \mathrm{~mm}$ (Sarkhad ve ark., 2020), selüloz \%47.60, pentozan \%7.09, lignin \%27.27, alkol benzende çözünürlük \%5.80, sicak su çözünürlüğü \%4.30, kül miktarı \%0.14 (Khutorshchikov, 1960), boyuna yönde daralma \%0.34, radyal yönde daralma \%3.40, teğet yönde daralma $\% 5.60$, hacimsel daralma \%8.20 (Jankowska ve ark., 2017), eğilme direnci $85.31 \mathrm{~N} / \mathrm{mm}^{2}$, liflere paralel çekme direnci $43.81 \mathrm{~N} / \mathrm{mm}^{2}$, liflere paralel basınç direnci $47.64 \mathrm{~N} / \mathrm{mm}^{2}$ (Demirci ve ark., 2016), elastikiyet modülü $6400.00 \mathrm{~N} / \mathrm{mm}^{2}$, enine kesitte janka sertlik $23.00 \mathrm{~N} / \mathrm{mm}^{2}$ (Jankowska ve ark., 2017), Coniophora puteana mantarına karşı ağırlık kayıpları \%19.81 (Kartal 2019) ve \%7.62 (Jankowska ve ark., 2017), radyal yönde 1s1 iletkenlik değeri $0.124 \mathrm{~W} / \mathrm{mK}$, teğet yönde 1s1 iletkenlik değeri $0.131 \mathrm{~W} / \mathrm{mK}$ ve enine yönde 1s1 iletkenlik değeri $0.160 \mathrm{~W} / \mathrm{mK}$ (Jankowska ve ark., 2013) olarak belirlenmiştir.

Bu bilgiler 1şığında bu ağaç türüne ait yüzey pürüzlülüğü parametrelerinin ve shore D sertlik değerinin araştırılmadığı literatürde görülmektedir.

$\mathrm{Bu}$ çalışmada, 1sıl işlem (ThermoWood) görmüş ve görmemiş Sibirya çamından hazırlanan örnekler üzerinde farklı numaralı zımparalar uygulandıktan sonra yüzey pürüzlülüğüne ait parametrelerden $R_{\mathrm{a}}, R_{\mathrm{z}}$ ve $R_{\mathrm{q}}$ değerleri ve shore $\mathrm{D}$ sertlik değerleri araştırılmıştır. Literatürde bu ağaç türüne 1sıl işlem uygulaması sonrasında yüzey pürüzlülüğü çalışmasının yapıldığ1 görülmemiştir. Elde edilen sonuçların bu ağaç türüne ait literatüre önemli bilgiler sunacağı düşünülmektedir.

\section{Materyal}

\subsection{Ahşap Malzemenin Temin Edilmesi}

Sibirya çamı (Pinus sibirica) odunu Düzce'de faaliyet gösteren Arın Orman Ürünleri'nden temin edilmiştir. Yüzey pürüzlülüğü ölçümleri için deney örnekleri $100 \times 10 \times$ $2 \mathrm{~cm}$ boyutlarında 6'şar adet olacak şekilde alınmış, daha sonra bu örneklere ISO 554 (1976) standardına göre iklimlendirme işlemleri yapılmıştır. 


\subsection{Metot}

\subsubsection{Isıl İşlem Uygulaması}

Isıl işlem uygulaması Bolu Gerede Organize Sanayi Bölgesi’nde (Bolu) bulunan Nova Orman Ürünleri San. Tic. A.Ş.'nde bilgisayar destekli firınlarda $212^{\circ} \mathrm{C}$ 'de 2 saat süre olacak şekilde yapılmıştır. ThermoWood metoduna göre isıl işlem uygulaması ThermoWood kitabında anlatıldığı metot ile uygulanmıştır (Anonim, 2003).

\subsubsection{Zımparalama İşlemi}

$10 \times 10 \times 2 \mathrm{~cm}$ boyutlarında hazırlanmış olan 1sıl işlem görmüş ve görmemiş deney örneklerine ait yüzeylerine 80, 100, 120, 150, 180 ve 220 numaralı zımparalar uygulanmıştır.

\subsubsection{Yüzey Pürüzlülüğünün Belirlenmesi}

Farklı zımparalar uygulanmış deney örneklerine ait yüzey pürüzlülüğü ölçümleri ISO 16610-21, (2011) standardına göre, JD - 520 model pürüzlülük test cihazında (Beijing Jitai Tech Detection Device Co., Ltd., Çin) yapılmıştır. Ölçüm işleminde teğet yüzeylerden liflere dik yönde olacak şekilde örnek uzunluğu $2.5 \mathrm{~mm}$ ve örnek uzunluk sayısı (cut-off) 5 olacak şekilde yapılmıştır. Örnekler üzerinden 10 'ar ölçüm yapılmıştır. $R_{\mathrm{a}}, R_{\mathrm{z}}$ ve $R_{\mathrm{q}}$ parametreleri belirlenmiştir.

\subsubsection{Shore D Sertlik Değerinin Belirlenmesi}

Sibirya çamı odununun shore D sertlik değeri (Stand: model Ld-J Loyka ve Durometer: Shenzhen Yibai Network Technology Co., Ltd., Çin) 5 kg'lık yük uygulamalı olacak şekilde ASTM D 2240 (2010)'a göre 10 ölçüm alınarak yapılmıştır.
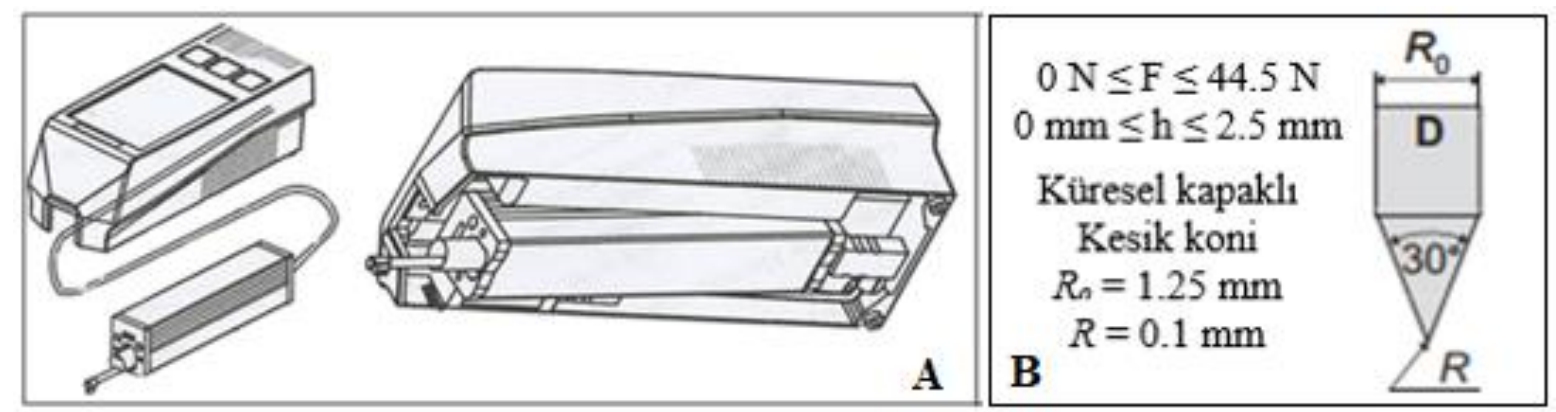

Şekil 1. Yüzey pürüzlülüğü cihazı (JD - 520 model) (A) ve shore D sertlik cihazı (B)

\subsection{5 İstatistiksel Analiz}

Bir SPSS programında varyans analizleri, homojenlik grupları, minimum ve maksimum değerleri, standart sapmaları, ortalamaları ve varyasyon katsayıları hesaplanmıştır.

\section{Bulgular ve Tartışmalar}

Isı1 işlem görmüş ve görmemiş Sibirya çamı odununa ait yüzey pürüzlülügü değerleri ve shore D sertlik değerleri için varyans analizi sonuçları ve SPSS sonuçları hesaplanmış olunup elde elden bu sonuçlar sırası ile Çizelge 1 ve Çizelge 2'de verilmiştir.

Çizelge 1'e göre, yüzey pürüzlülüğü parametreleri için faktör 1sıl işlem (A), faktör zımpara (B) ve bu faktörlerin etkileşiminin (AB) anlamlı olarak elde edildikleri görülmektedir. Buna ek olarak, shore D sertlik değeri için ısıl işlem faktörü de anlamlı olarak elde edilmiştir. 
Çizelge 1. Yüzey pürüzlülügü ve shore D sertlik değeri için varyans analizi sonuçları

\begin{tabular}{|c|c|c|c|c|c|c|}
\hline Test & Varyans Kaynağı & Kareler Toplamı & Serbestlik Derecesi & Ortalama Kare & F Değeri & $\alpha \leq 0.05$ \\
\hline \multirow{5}{*}{$R_{\mathrm{a}}$} & İşlem (A) & 114.350 & 1 & 114.350 & 2177.528 & $0.000^{*}$ \\
\hline & Zımpara (B) & 335.020 & 5 & 67.004 & 1275.934 & $0.000^{*}$ \\
\hline & Etkileşim (AB) & 1.975 & 5 & 0.395 & 7.520 & $0.000^{*}$ \\
\hline & Hata & 5.671 & 108 & 0.053 & & \\
\hline & Toplam & 3533.467 & 120 & & & \\
\hline \multirow{5}{*}{$\boldsymbol{R}_{\mathbf{q}}$} & İşlem (A) & 168.450 & 1 & 168.450 & 1395.198 & $0.000^{*}$ \\
\hline & Zimpara (B) & 491.413 & 5 & 98.283 & 814.031 & $0.000^{*}$ \\
\hline & Etkileşim (AB) & 3.017 & 5 & 0.603 & 4.998 & $0.000^{*}$ \\
\hline & Hata & 13.039 & 108 & 0.121 & & \\
\hline & Toplam & 5663.732 & 120 & & & \\
\hline \multirow{5}{*}{$\boldsymbol{R}_{\mathrm{z}}$} & İşlem (A) & 3851.044 & 1 & 3851.044 & 368.393 & $0.000^{*}$ \\
\hline & Zimpara (B) & 10375.092 & 5 & 2075.018 & 198.497 & $0.000 *$ \\
\hline & Etkileşim (AB) & 213.697 & 5 & 42.739 & 4.088 & $0.002 *$ \\
\hline & Hata & 1128.993 & 108 & 10.454 & & \\
\hline & Toplam & 171575.783 & 120 & & & \\
\hline \multirow{3}{*}{$\begin{array}{c}\text { Shore } \\
\text { D }\end{array}$} & Isıl işlem & 288.800 & 1 & 288.800 & 96.267 & $0.000^{*}$ \\
\hline & Hata & 54.000 & 18 & 3.000 & & \\
\hline & Toplam & 22654.000 & 20 & & & \\
\hline
\end{tabular}

Çizelge 2'ye göre, zımpara numarasının artması ile pürüzlülük değerlerinin azaldığı görülmektedir. Literatürde zımpara üzerine yapılan araştırmalarda benzer sonuçların elde edildiği görülmektedir (Çamlıbel ve Ayata, 2020, Hızıroğlu ve ark., 2014, Söğütlü ve ark., 2016, Leite ve ark., 2019, Palermo ve ark., 2014, Ayata, 2020). Bunun sebebi olarak ahşap malzeme yüzeyinin aşındırarak işlem yapan zımparanın sahip olduğu tanecik sayısının fazla olması ile tanecik başına düşen iş miktarının azalması ve bu taneciklerin, işlem esnasında yüzeyde oluşturduğu vadilerin ölçüsünde etkili olmasından dolayı kaynaklanabileceği şeklinde ifade edilmiştir (Söğütlü 2005). Isıl işlemden sonra $R_{\mathrm{a}}, R_{\mathrm{z}}$ ve $R_{\mathrm{q}}$ parametrelerine ait sonuçların azaldığ görülmektedir. En yüksek $R_{\mathrm{a}}$ ve $R_{\mathrm{Z}} 80$ numaralı zımpara ile zımparalanmış deney örneklerinde elde edilirken, bunu 100, 120, 150, 180 ve 220 numaralı zımparalar takip etmiştir (Çizelge 2). Çalışma sonuçları 1sıl işlemli ahşap çalışmalarına sahip önceki çalışmalarla uyumluluk göstermiştir (Karlinasari ve ark., 2018; Salca ve Hızıroğlu, 2014; Priada ve Hızıroğlu, 2013; Palermo ve ark., 2014; Aytin, 2013; Ayata ve ark., 2018; Kasemsiri ve ark., 2012).

Karlinasari ve ark., (2018) araştırmalarında, sengon, jabon ve akasya ahşap numuneler üzerinde yapılan yüzey pürüzlülüğü sonuçlarına göre, $120^{\circ} \mathrm{C}, 150^{\circ} \mathrm{C}$ ve $180^{\circ} \mathrm{C}$ 'de sıcaklıklarda 2 ve 6 saat süre ile yapılan ısıl işlem uygulamalarından sonra $R_{\text {a }}$ parametrelerinin azaldığını belirlemişlerdir. Ayata ve ark., (2018) çalışmalarında; ThermoWood ${ }^{\circledR}$ metoduna göre $212^{\circ} \mathrm{C}^{\prime}$ de 1 saat ve 2 saat süreyle 1 sıl işlem görmüş kayın, sarıçam ve meşe örnekleri için uygulanmış 180 kumluk kalibre zımparalama işleminden sonra 1sıl işlem süresinin artması ile $R_{\mathrm{a}}, R_{\mathrm{Z}}$ ve $R_{\mathrm{q}}$ parametrelerinin azaldığını rapor etmişlerdir. Aytin (2013) araştırmasında, 1sıl işlemli ve işlemsiz yabani kiraz odunu için yapılan yüzey pürüzlülüğü testlerinden sonra, uygulanan 1 sıl işlemde sıcaklık ve sürenin artması ile $R_{\text {a }}$ parametresinin azaldığını bildirmiştir. Perçin ve ark., (2016) tarafindan 1 sıl işlemsiz (kontrol) ve 1 sil işlemli $\left(150^{\circ} \mathrm{C}, 170^{\circ} \mathrm{C}, 190^{\circ} \mathrm{C}\right.$ ve $210^{\circ} \mathrm{C}$ 'lerde 2,5 ve 8 saat sürelerinden oluşan isıl işlemi varyasyonlar) meşe odununa ait deney örnekleri üzerinde belirlemiş olan yüzey pürüzlülüğü $R_{\mathrm{a}}$ parametresinin 1 sıl işlem tarafından azaldığını rapor etmişlerdir. Priada ve Hızıroğlu (2013) çalışmalarında 1sıl işlemli ve işlemsiz güney kırmızı meşesi, mahogany ve loblolly çamı odunlarına ait deney örnekleri üzerinde yapılan yüzey pürüzlülüğü sonuçlarına göre, $130^{\circ} \mathrm{C}$ ve $220^{\circ} \mathrm{C}$ 'de sicaklılarda 2 ve 8 saat süre ile yapılan 1 sil işlem uygulamalarından sonra $R_{\mathrm{a}}$ ve $R_{\mathrm{z}}$ parametrelerinin azaldığını 
söylemişlerdir. Salca ve Hızıroğlu (2014) çalışmalarında ısıl işlem uygulanmış ve uygulanmamış güney kırmızı meşesi, adi kızılağaç, loblolly çamı ve lale ağacı odunlarına ait deney örneklerinde belirlenmiş olan yüzey pürüzlülüğü verilerine göre, $120^{\circ} \mathrm{C}$ ve $190^{\circ} \mathrm{C}$ 'ye sahip sıcaklılarda 3 ve 6 saat süre ile yapılan isıl işlemlerden sonra $R_{\mathrm{a}}$ ve $R_{\mathrm{z}}$ parametrelerinin azaldığını bildirmişlerdir. Kasemsiri ve ark., (2012) tarafından kurşun kalem ardıcı odunu için $120^{\circ} \mathrm{C}, 160^{\circ} \mathrm{C}$ ve $190^{\circ} \mathrm{C}$ 'de sicaklıklarda 2 ve 8 saat süreye sahip varyasyonlardan oluşan isıl işlem uygulamalarından sonra $R_{\mathrm{a}}, R_{\mathrm{z}}$ ve $R_{\max }$ parametrelerinin azaldığ 1 bildirilmiştir.

Çizelge 2. Yüzey pürüzlülügü parametrelerine ve shore D sertliğine ait sonuçlar

\begin{tabular}{|c|c|c|c|c|c|c|c|c|c|c|}
\hline Test & $\begin{array}{c}\text { Zımpara } \\
\text { Numarası }\end{array}$ & İşlem & $\begin{array}{l}\text { Ölçüm } \\
\text { Sayısı }\end{array}$ & $\begin{array}{l}\text { Orta- } \\
\text { lama }\end{array}$ & \begin{tabular}{|c} 
Isıl İşlem \\
Sonrası \\
Azalıș (\%)
\end{tabular} & $\begin{array}{c}\text { Standart } \\
\text { Sapma }\end{array}$ & \begin{tabular}{|c|} 
Homo- \\
jenlik \\
Grubu
\end{tabular} & $\begin{array}{l}\text { Mini- } \\
\text { mum }\end{array}$ & $\begin{array}{c}\text { Maksi- } \\
\text { mum }\end{array}$ & $\begin{array}{c}\text { Varyasyon } \\
\text { Katsayısı }\end{array}$ \\
\hline \multirow{12}{*}{ 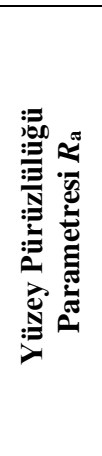 } & \multirow{2}{*}{80} & Kontrol & 10 & 8.490 & \multirow{2}{*}{22.16} & 0.17 & $\mathrm{~A}^{*}$ & 8.110 & 8.786 & 2.00 \\
\hline & & Isıl işlemli & 10 & 6.609 & & 0.24 & $\mathrm{C}$ & 6.080 & 6.967 & 3.66 \\
\hline & \multirow{2}{*}{100} & Kontrol & 10 & \begin{tabular}{|l|}
7.641 \\
\end{tabular} & \multirow{2}{*}{26.25} & 0.22 & $\mathrm{~B}$ & \begin{tabular}{|l|}
7.379 \\
\end{tabular} & 8.009 & 2.84 \\
\hline & & Isıl işlemli & 10 & 5.635 & & 0.37 & $\mathrm{D}$ & 5.147 & 6.176 & 6.52 \\
\hline & \multirow{2}{*}{120} & \begin{tabular}{|l|} 
Kontrol \\
\end{tabular} & 10 & 6.685 & \multirow{2}{*}{36.42} & 0.29 & $\mathrm{C}$ & 6.136 & 7.001 & 4.31 \\
\hline & & Issl işlemli & 10 & 4.251 & & 0.17 & $\mathrm{~F}$ & 4.037 & 4.594 & 4.07 \\
\hline & \multirow{2}{*}{150} & Kontrol & 10 & 5.360 & \multirow{2}{*}{35.71} & 0.18 & $E$ & 5.007 & 5.578 & 3.34 \\
\hline & & Isıl işlemli & 10 & 3.446 & & 0.19 & $\mathrm{H}$ & 3.228 & 3.771 & 5.49 \\
\hline & \multirow{2}{*}{180} & Kontrol & 10 & 4.298 & \multirow{2}{*}{36.38} & 0.23 & $\mathrm{~F}$ & 4.106 & 4.698 & 5.37 \\
\hline & & Isıl işlemli & 10 & 2.734 & & 0.20 & I & 2.340 & 3.009 & 7.48 \\
\hline & \multirow{2}{*}{220} & Kontrol & 10 & 3.763 & \multirow{2}{*}{50.88} & 0.24 & $\mathrm{G}$ & 3.364 & 4.065 & 6.35 \\
\hline & & Isıl işlemli & 10 & 1.848 & & 0.17 & $\mathrm{~J} * *$ & 1.497 & 2.042 & 9.10 \\
\hline \multirow{12}{*}{ 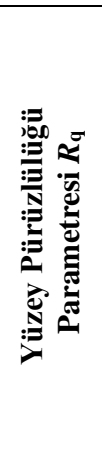 } & \multirow{2}{*}{80} & \begin{tabular}{|l|} 
Kontrol \\
\end{tabular} & 10 & 10.417 & \multirow{2}{*}{20.59} & 0.18 & $\mathrm{~A}^{*}$ & 10.068 & 10.803 & 1.72 \\
\hline & & Isıl işlemli & 10 & 8.272 & & 0.33 & $\mathrm{C}$ & 7.661 & 8.708 & 3.96 \\
\hline & \multirow{2}{*}{100} & Kontrol & 10 & 9.700 & \multirow{2}{*}{24.27} & 0.33 & $\mathrm{~B}$ & 9.148 & 10.106 & 3.38 \\
\hline & & Issl işlemli & 10 & 7.346 & & 0.65 & $\mathrm{D}$ & 6.591 & 8.476 & 8.90 \\
\hline & \multirow{2}{*}{120} & Kontrol & 10 & 8.367 & \multirow{2}{*}{34.93} & 0.35 & $\mathrm{C}$ & 7.678 & 8.704 & 4.13 \\
\hline & & Isıl işlemli & 10 & 5.444 & & 0.32 & $\mathrm{~F}$ & 5.056 & 5.867 & 5.86 \\
\hline & \multirow{2}{*}{150} & Kontrol & 10 & 6.871 & \multirow{2}{*}{34.71} & 0.28 & $\mathrm{E}$ & 6.337 & 7.162 & 4.01 \\
\hline & & Isıl işlemli & 10 & 4.486 & & 0.23 & $\mathrm{H}$ & 4.166 & 4.843 & 5.17 \\
\hline & \multirow{2}{*}{180} & Kontrol & 10 & 5.370 & \multirow{2}{*}{35.28} & 0.30 & FG & 5.140 & 5.874 & 5.66 \\
\hline & & Isıl işlemli & 10 & 3.476 & & 0.29 & $\mathrm{I}$ & 2.943 & 3.887 & 8.40 \\
\hline & & Kontrol & 10 & 5.065 & & 0.36 & $\mathrm{G}$ & 4.404 & 5.539 & 7.19 \\
\hline & 220 & Isıl işlemli & 10 & 2.550 & 49.66 & 0.34 & $\mathrm{~J} * *$ & 2.014 & 3.011 & 13.19 \\
\hline & & Kontrol & 10 & 53.080 & & 1.90 & $\mathrm{~A}^{*}$ & 51.221 & \begin{tabular}{|l|}
57.603 \\
\end{tabular} & 3.58 \\
\hline & 80 & Isıl işlemli & 10 & 45.503 & 14.27 & 4.31 & $\mathrm{~B}$ & 39.509 & 53.650 & 9.47 \\
\hline & & Kontrol & 10 & 50.736 & & 1.08 & $\mathrm{~A}$ & 48.684 & \begin{tabular}{|l|}
52.738 \\
\end{tabular} & 2.12 \\
\hline & 100 & Isıl işlemli & 10 & 40.256 & 20.66 & 5.52 & $\mathrm{C}$ & 34.345 & 48.095 & 13.72 \\
\hline : & & Kontrol & 10 & 44.319 & & 2.56 & $\mathrm{~B}$ & 41.995 & 48.504 & 5.77 \\
\hline : & 120 & Isıl işlemli & 10 & 32.210 & 27.32 & 4.26 & $\mathrm{D}$ & 27.843 & \begin{tabular}{|l|}
39.713 \\
\end{tabular} & 13.22 \\
\hline$\stackrel{\Xi}{\Xi}$ & 150 & Kontrol & 10 & 40.159 & & 2.68 & $\mathrm{C}$ & 36.044 & 44.463 & 6.69 \\
\hline 鹿 & 150 & Isıl işlemli & 10 & 26.023 & & 1.99 & $\mathrm{E}$ & 23.764 & \begin{tabular}{|l|}
29.732 \\
\end{tabular} & 7.64 \\
\hline$\stackrel{\mathbb{S}}{\Xi}$ & & Kontrol & 10 & 30.051 & & 2.20 & $\mathrm{D}$ & 27.460 & \begin{tabular}{|l|}
34.124 \\
\end{tabular} & 7.32 \\
\hline & 180 & Isıl işlemli & 10 & 21.288 & 16 & 3.12 & $\mathrm{~F}$ & 17.216 & 26.509 & 14.64 \\
\hline & & Kontrol & 10 & 31.985 & & 3.62 & $\mathrm{D}$ & 26.925 & 35.934 & 11.31 \\
\hline & 220 & Isıl işlemli & 10 & 17.069 & 46.63 & 2.86 & $\mathrm{G}$ & 13.138 & 20.877 & 16.76 \\
\hline & & Kontrol & 10 & 37.20 & & 1.32 & $\mathrm{~A}^{*}$ & 36.00 & 39.00 & 3.55 \\
\hline Sh & rtlik & Isıl işlemli & 10 & 29.60 & & 2.07 & $\mathrm{~B} * *$ & 28.00 & 35.00 & 6.99 \\
\hline
\end{tabular}

Çizelge 2'de verilen shore D sertlik değeri sonuçlarına göre 1sıl işlemiz örnekte 37.20 iken 1sıl işlemli örnekte 29.60 olduğu, buna göre \%27.68'lik bir azalma görülmektedir. Isı1 işlemden sonra sertlik değerinin azaldığı sonucuna ulaşılmıştır. Esteves ve ark., (2021) tarafından yapılan araştırmada da 1 sıl işlem sonrası shore D sertlik değerinin azaldığı bildirilmiştir. Literatürde ahşap malzemedeki mukavemet özelliklerindeki azalmaların, 1sıl işlemlerden sonra 1sıl bozulma oranı ve madde kayıpları ile ilişkili olduğu, mukavemetteki 
azalma temel olarak ahşap polimerlerinin depolimerizasyon reaksiyonlarından kaynaklandiğ (Kotilainen, 2000), performans kaybının nedenleri arasında 1sıya karşı selüloz ve ligninden daha az kararlı olan hemiselülozların bozulmasının olduğu ve hemiselülozlardaki değişikliklerin, yüksek sıcaklıklarda 1sıtılan ahşabın mukavemet özellikleri üzerinde önemli bir rol oynadığı (Hillis, 2005) şeklinde bildirilmiştir. Literatürde sertliğin ağaçtan ağaca büyük farklar gösterdiği şeklinde ifade edilmiştir (Şanıvar ve Zorlu, 1980). Sertlik, bir yüzeyin çökmesini, çizilmesini veya kesilmesini zorlaştıran özelliktir. Genel olarak, ahşap ne kadar sert olursa, aşınmaya o kadar iyi direnir, yükler altında o kadar az ezilir ve daha iyi cilalanabilmektedir. Öte yandan, daha sert olan ahşabın aletlerle kesilmesi daha zordur, çivilenmesi daha zordur ve çivileme sırasında yarılma olasılığı daha yüksektir. Sertlik, döşeme, mobilya ve alet saplarında özellikle önemli olmaktadır (Anderson, 1967).

\section{Sonuçlar ve Öneriler}

Bu çalışmada, yapılan denemeler sonunda aşağıdaki sonuçlar elde edilmiştir:

- Bütün testler için varyans analizleri anlamlı olarak elde edilmiştir.

- Isıl işlem ile shore $\mathrm{D}$ sertlik ve yüzey pürüzlülügü parametrelerinin $\left(R_{\mathrm{a}}, R_{\mathrm{z}}\right.$ ve $\left.R_{\mathrm{q}}\right)$ azaldığ 1 sonucuna ulaşılmıştır.

- Zımpara numarasının 80'den 220'ye çıkması ile yüzey pürüzlülüğü parametrelerinin ( $R_{\mathrm{a}}, R_{\mathrm{z}}$ ve $R_{\mathrm{q}}$ ) azaldığ 1 görülmüş olunup, yüzey kalitesinde iyileşme elde edilmiştir.

- Is1l işlemden sonra; shore D sertlik değerinde $\% 20.43, R_{\mathrm{a}}$ parametrelerinde 80 numarada \%22.16, 100 numarada \%26.25, 120 numarada \%36.42, 150 numarada \%35.71, 180 numarada $\% 36.38$ ve 220 numarada $\% 50.88$ olarak azalmaların meydana geldiği belirlenmiştir.

$\mathrm{Bu}$ ağaç türüne ait mobilya ve iç mekan tasarımı üzerine alanlarında önemli sonuçların elde edilmesi için Sibirya odunu ahşabında çeşitli üst yüzey işlemlerinin (vernik, UV sistem vernik, boya, vb.) uygulanması ve elde edilecek olan malzemeler üzerinde doğal ve yapay (UV-A,B,C veya Xenon gibi lambalarına karşı) yaşlandırma işlemelerinin uygulanması ve gerekli yüzey testlerinin (renk, salınımsal sertlik, yüzeye yapışma direnci, parlaklık, çizilme, vb.,) yapılması önerilmektedir.

\section{Teşekkür}

Yazar ahşap malzemelerin temini için Arın Orman Ürünleri'ne (Düzce) ve 1sıl işlem uygulamaları için NOVA ThermoWood Fabrikasına (Bolu-Gerede) teşekkür etmektedir.

\section{Kaynaklar}

Anderson, L.O., (1967), Selection and Use of Wood Products for Home and Farm Buildings, Agricultural Information Bulletin No. 311, Washington, D.C.: U.S. Government Printing Office.

Anonim, (2003), ThermoWood® Handbook, Finnish ThermoWood Association, Helsinki, Finland.

ASTM D 2240, (2010), Standard test method for rubber property-durometer hardness, American Society for Testing and Materials, West Conshohocken, Pennsylvania, United States.

Ayata, U., Gurleyen, T., Gurleyen, L., Cakicier, N., (2018), Determination of surface roughness parameters of heat-treated and untreated scotch pine, oak and beech woods, Furniture and Wooden Material Research Journal, 1(1), 46-50. DOI: 10.33725/mamad.433945 
Aytin, A., (2013), Yabani kiraz (Cerasus avium (1.) Monench) odununun fiziksel, mekanik ve teknolojik özellikleri üzerine yüksek sıcaklık uygulamasının etkisi, Düzce Üniversitesi, Fen Bilimleri Enstitüsü, Doktora Tezi, Düzce.

Ayata, Ü., (2020), Ayous odununun bazı teknolojik özelliklerinin belirlenmesi ve 1s1l işlemden sonra renk ve parlaklık özellikleri, Mobilya ve Ahşap Malzeme Araştırmaları Dergisi, 3(1), 22-33. DOI: 10.33725/mamad.724596.

Çamlıbel, O., Ayata, Ü., (2020), Monkey pod odununda yüzey pürüzlülüğü parametrelerinin ve shore-D sertlik değerinin belirlenmesi, Mobilya ve Ahşap Malzeme Araştırmalar Dergisi, 3(2), 93-100. DOI: 10.33725/mamad.827211.

Demirci, S., Acar, M., Balıkcı, E., Diler, H., Erdil, Y.Z., (2016), Comparison of some physical and mechanical properties of various heat-treated and untreated wood, IFC2016 International Furniture Congress, 13-15 October 2016, Turkey, 121-127.

Esteves, B., Şahin, S., Ayata, Ü., Domingos, I., Ferreira, J., Gurleyen, L., (2021), The effect of heat treatment on shore D hardness of some wood species, Bioresources, 16(1), 1482-1495. DOI: 10.15376/biores.16.1.1482-1495.

Hillis, W.E., (1984), High temperature and chemical effects on wood stability, Wood Science and Technology, 18, 281-293.

Hiziroglu, S., Zhong, Z.W., Ong, W.K., (2014), Evaluating of bonding strength of pine, oak and nyatoh wood species related to their surface roughness, Measurement, 49, 397-400. DOI: 10.1016/j.measurement.2013.11.053.

ISO 554, (1976), Standard atmospheres for conditioning and/or testing, International Standardization Organization, Geneva, Switzerland.

ISO 16610-21, (2011), Geometrical Product Specifications (GPS) - Filtration - Part 21: Linear Profile Filters: Gaussian Filters, Standard.

Jankowska, A., Wójcik, A., Jenczyk-Tołłoczko, I., (2013), Determination of thermal properties of wood of Pinus sibirica Du Tour, Annals of Warsaw University of Life Sciences - SGGW Forestry and Wood Technology, No. 82/2013.

Jankowska, A., Anders, B., Mastyna, B., (2017), Characteristic technical properties of Siberian yellow pine (Pinus sibirica Du Tour.) wood, Sylwan, 161(9), 756-762.

Karlinasari, L., Lestari, A.T., Priadi, T., (2018), Evaluation of surface roughness and wettability of heat-treated, fast-growing tropical wood species sengon (Paraserianthes falcataria (L.) I.C. Nielsen), jabon (Anthocephalus cadamba (Roxb.) Miq), and acacia (Acacia mangium Willd.), International Wood Products Journal, 9(3), 142-148. DOI: 10.1080/20426445.2018.1516918.

Kartal, Z.N., (2019), Borik asit ve polikaprolakton modifikasyonunun ahşabın biyolojik dayanım ve boyut stabilizasyonu ile bor yıkanmasına etkisi, Bursa Teknik Üniversitesi, Fen Bilimleri Enstitüsü, Yüksek Lisans Tezi, Bursa.

Kasemsiri, P., Hiziroglu, Rimdusit, S., (2012), Characterization of heat treated eastern redcedar (Juniperus virginiana L.), Journal of Materials Processing Technology, 212(6), 1324-1330. DOI: 10.1016/j.jmatprotec.2011.12.019.

Khutorshchikov, I.S., (1960), Bumazhnaya Promyshlennost, (1): 15.

Kotilainen, R., (2000), Chemical Kotilainen R. Chemical changes in wood during heating at 150-260, 1C. PhD thesis, Jyva "skyla" University. Research report 80, Finland. 
Kuznetsova, G.V., (2007), The variation among clima types of Siberian stone pine (Pinus sibirica Du Tour) in the south of Krasnoyarskiy kray, Khvoynyye borealnoy zony, 24(45), 423.

Leite, S.S., Jesus, G.M.K., Alves, M.C.S., Valarelli, I.D., Bueno, M.A.P., Christiane, F., Magorbo, R.D., Alexandre Moizes, F.A., Salvadeo, V.M., (2019), Analysis of the parameters affecting the surface sanding of Pinus elliottii and Corymbia citriodora wood species, BioResources, 14(2), 2773-2783. DOI: 10.15376/biores.14.2.2773-2783.

Matveeva, R.N., Butorova, O.F., Bratilova, N.P., (2003), Useful properties and methods of reproduction of Pinus sibirica (Krasnoyarsk: SibGTU) p 154.

Palermo, G.P.M., Latorraca, J.V.F., Moura, L.F., Nolasco, A.M., Carvalho, A.M., Garcia, R.A., (2014), Surface roughness of heat treated Eucalyptus grandis wood, Maderas. Ciencia y tecnología, 16(1), 3-12: DOI: 10.4067/S0718-221X2014005000001.

Perçin, O., Uzun, O., Saçl1, C., (2016), Determination of the some physical properties and surface roughness of heat-treated oak (Quercus petraea L.) wood, IFC2016 International Furniture Congress 13-15 October 2016, 359-363.

Priadi, T., Hiziroglu, S., (2013), Characterization of heat-treated wood species, Materials and Design, 49: 575-582. DOI: 10.1016/j.matdes.2012.12.067.

Rogachev, A.D., Salakhutdinov, N.F., (2015), Chemical composition of Pinus sibirica (Pinaceae), Chemistry \& Biodiversity,12: 1-53.

Salca, E.A., Hiziroglu, S., (2014), Evaluation of hardness and surface quality of different wood speciesas function of heat treatment, Materials and Design, 62: 416-423. DOI: 10.1016/j.matdes.2014.05.029.

Sarkhad, M., Ishiguri, F., Nezu, I., Tumenjargal, B., Takahashi, Y., Baasan, B., Chultem, G., Ohshima, J., Yokota, S., (2020), Preliminary evaluation for quality of dimension lumber in four common softwoods in Mongolia, Journal of Wood Science, 66: 72. DOI: 10.1186/s10086-020-01919-7.

Shikov, A.N., Makarov, V.G., Ryzhenkov, V.E., (2004), Plant fixed oils and oil extracts: technology, standardization, properties, Russian Doctor, Moscow.

Sögütlü, C., (2005), Bazı faktörlerin zımparalanma ağaç malzeme yüzey pürüzlülüğüne etkisi, Politeknik Dergisi, 8(4), 345-350.

Söğütlü, C., Nzokou, P., Koc, I., Tutgun, R., Döngel, N., (2016), The effects of surface roughness on varnish adhesion strength of wood materials, Journal of Coatings Technology and Research, 13(5), 863-870. DOI: 10.1007/s11998-016-9805-5.

Şanıvar, N., Zorlu, İ., (1980), Ağaçişleri Gereç Bilgisi Temel Ders Kitabı, Mesleki Ve Teknik Öğretim Kitapları, Milli Eğitim Basımevi, İstanbul, Etüd ve Programlama Dairesi Yayınları No: 43, 472 sayfa.

Wang, C., (2011), Study on the introduction and seed origin experiment of Pinus sibirica, Thesis for M.S., Northeast Forestry University, Supervisor: Jiang J., p. 1-7.

Zhuk, E.A., Goroshkevich, S.N., (2012), Factors of intraspecies variation of Siberian stone pine in latitudinal and altitudinal transects, Khvoynyye Borealnoy Zony, 27(3-4), 61-66. 